\title{
Morphology and Mechanical Properties of Al- TiC Nanocomposite Processed via Ball Milling Technique
}

\author{
F. S. Hamid ${ }^{1 *}$, A. EL-Nikhaily ${ }^{1}$, H. R. Abd Ellatif ${ }^{2}$, O. A. El kady ${ }^{3}$ \\ ${ }^{1}$ Faculty of Technology and Education, Suez University, Suez, Egypt. \\ ${ }^{2}$ Metallurgical \& Material Engineering, Faculty of Petroleum \& Mining Engineering, Suez University, Egypt. \\ ${ }^{3}$ Powder Technology Division, Manufacturing Technology Department, Central Metallurgical R \& D Institute (CMRDI), P.O. 87, Helwan, \\ 11421 Cairo, Egypt.
}

*Corresponding author: E-mail: fadel.shaban @ suezuni.edu.eg, Tel: (+2) 01009503248

Received: 31 January 2021

Revised: 19 March 2021

Accepted for publication: 23 May 202

Published online 30 June 2021

\section{Abstract}

Al-TiC nanocomposites are prepared by powder metallurgy technique. The effect of milling time and TiC percent on the mechanical properties and microstructure are studied. Nano TiC powders with 5, 10, and $20 \mathrm{wt}$. \% is added to the $\mathrm{Al}$ matrix. The mixed powders are mechanically milled by a 35:1 ball to powder ratio and $110 \mathrm{rpm}$ for $6,12,24$, and $48 \mathrm{hr}$. milling time (MT). Mixed powders are compacted by a uniaxial press under $600 \mathrm{Mpa}$ and sintered at $600{ }^{\circ} \mathrm{C}$ for $1 \mathrm{hr}$. in a vacuum furnace. According to Archimedes' principle, the density was estimated, which indicated it is decreasing for $6 \mathrm{hr}$. milling time, followed by an increase for 12 and $24 \mathrm{hrs}$., then another decreasing for $48 \mathrm{hrs}$. The addition of nano TiC increases the density values gradually by increasing its percent. Both the phase composition and microstructure of both composite powders and sintered samples are examined using XRD \& FE-SEM, respectively. XRD results indicated forming the aluminum carbide $\left(\mathrm{Al}_{4} \mathrm{C}_{3}\right)$ phase that is formed during the sintering process. The microstructure shows the homogeneous distribution of $\mathrm{TiC}$ on the $\mathrm{Al}$ matrix and the reduction of $\mathrm{Al}$ particle size by increasing both milling time and $\mathrm{TiC}$ percent. Hardness, compression strength, and wear resistance are improved by increasing TiC content and MT up to 24 hours. Al-20 wt. \% TiC composite with $24 \mathrm{hr}$. milling time exhibited the highest hardness $(196.5667 \mathrm{HV})$ and the lowest wear rate $(0.001 \mathrm{~g} / \mathrm{min})$.

Keywords: Al-TiC; Mechanical milling; Hardness; Compression; Wear rate.

\section{Introduction}

The aluminium composite prepared by powder metallurgy technique (PM) has good mechanical and fatigue properties. Low density, high thermal and electrical conductivities, excellent machinability are achieved. Also, good response to a variety of finishing processes, and which are competitive on a cost per unit volume basis [1][2][3]. The primary driver for the use of aluminium composites prepared by PM is manufacturing net or near-net shape products [4]. Aluminium PM can replace other PM in specific applications on a direct basis. However, in terms of the potential for ferrous-based product substitution, each potential application needs to be considered on a caseby-case basis [5][6][7].

Titanium carbide is a ceramic material that has high hardness and strength. It is used as a reinforcement to produce metal matrix composites (MMCs) [2]. These are used in the automobile, airplanes, cutting tools, and space industries. Yang et al. stated that hard TiC particles help in improving the soft matrix in terms of hardness and wear resistance [8][9][10]. The improvement in the properties of the prepared composites depends on the percent and distribution of TiC particles, the strength of the particle-matrix boundary, and the mechanical properties of the matrix. Al-TiC composites occupy a unique position in the family of metal matrix composites due to their excellent wear/stiffness, the strength-to-weight ratio, with good mechanical properties [11][12][13]. Al-TiC composite has been found to possess good strength and stiffness. It has been reported that $\mathrm{TiC}$ reinforced $\mathrm{Al}$ matrix composites exhibit higher stiffness and ductility than TiB2 [14][15]. This may be due to the interfacial bonding strength in the Al-TiC composite caused by the tendency for nucleation of solid phase on the sample surfaces [16][17].

Ceramic carbides such as $\mathrm{TiC}$ have a high melting point, thermal stability, and good tribological properties. They also have a low coefficient of friction, and excellent wear resistance. This is attributed to their 
high hardness. Further enhancement of the mechanical properties can be obtained using nano-sized reinforcing particles [18][19][20]. Decreasing reinforcement particle size to nano-size range brings a superior increase in mechanical strength of composites [21][22][23]. As such, more stress is required for dislocation movement due to the Orowan strengthening mechanism [24][25][26]. Mechanical alloying (MA) is a suitable technique to prevents the agglomeration of nanoparticles [27][28]. Mechanical alloying is a powerful solid-state powder processing technique that involves repeated deformation, cold welding, and fracture in a high-energy ball mill [29][30].

The objectives of the present work are to improve the microstructure and mechanical properties of Al-TiC composites prepared by powder metallurgy by studying the effect of $\mathrm{TiC}$ percent and milling time for automotive industry applications.

\section{MATERIAL AND METHODS}

\subsection{Materials}

Aluminium (Al) powder with $99.5 \%$ purity (supplied by Alpha Chemicals, USA) with an average particle size of $30 \mu \mathrm{m}$ is used as a metal matrix. Titanium carbide (TiC) powder with $99.7 \%$ purity (supplied by Inframat Advanced Materials, LLC, Manchester, USA) with an average size of $1 \mu \mathrm{m}$ is used as a reinforcement. 5, 10, and $20 \mathrm{wt}$. \% $\mathrm{TiC}$ is mixed with aluminium powder using a ball milling technique at various milling times of $6,12,24$, and $48 \mathrm{hr}$. The powders are mixed in Stainless steel vial fabricated from AISI 316 grade steel the diameter of the inside up to $100 \mathrm{~mm}$, and hardened chromium steel balls with two different sizes of 10 and $14 \mathrm{~mm}$ diameters were used for the milling process and protected from oxidation using high pure argon gas, by 35:1 ball to powder ratio (BPR) and $110 \mathrm{rpm}$. Stearic acid (3\% wt.) is used as a process controlling agent (PCA). A mixing process was carried out in the Faculty of Technology and Education, Suez University. Fig.1 shows the composition and nomenclature of prepared specimens.

\subsection{Sintering Process}

The milled powders are compacted using a uniaxial cold press at $600 \mathrm{MPa}$. Next, the compacted specimens are sintered at $600{ }^{\circ} \mathrm{C}$ for $60 \mathrm{~min}$ in a vacuum furnace. The sintering process is achieved by $3^{\circ} \mathrm{C} / \mathrm{min}$ heating rate from room temperature up to $250{ }^{\circ} \mathrm{C}$ with dwell time at $15 \mathrm{~min}$ for dewaxing then raising the temperature to $600{ }^{\circ} \mathrm{C}$ by the same rate withholding time $60 \mathrm{~min}$ to complete the sintering process. The performed thermal heating cycle is illustrated in Fig. 1.

\subsection{Composite Characterization}

According to Archimedes ' principle, the actual density of the sintered specimens is determined per ASTM D1217 standard. The relative of the sintered specimens is measured using water as a floating liquid according to MPIF standard 42, 1998.

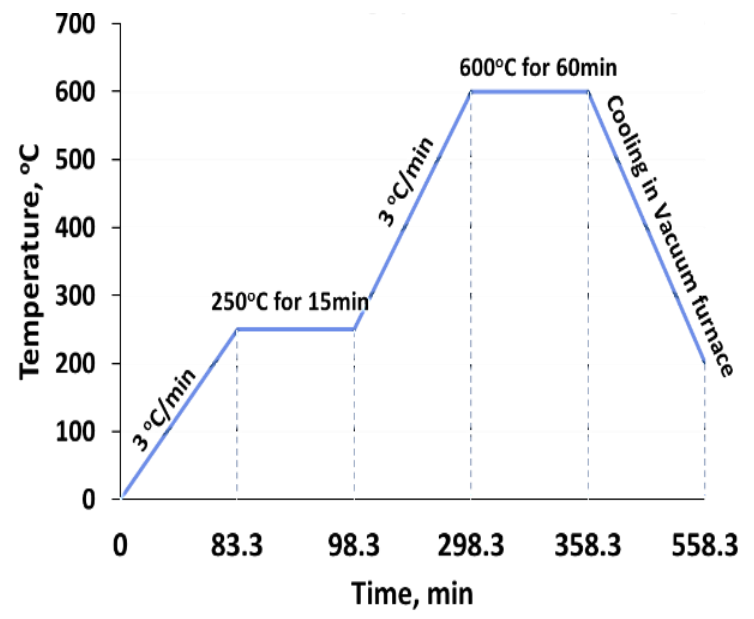

Fig. 1 Heating cycle of the sintering process for AlTiC specimens.

The density of Al-TiC composites calculated using the following equations:

$$
\rho_{c}=\frac{m}{v}
$$

The density of Al-TiC calculated using the following equation:

$$
\frac{1}{\rho_{c}}=\frac{w_{m}}{\rho_{m}}+\frac{w_{r}}{\rho_{r}}
$$

Where, $\rho$ is the density of specimen, $w$ is weight fraction. Subscripts $m, r$, and c refer to the matrix, reinforcement, and composite, respectively.

$\left(\rho_{c}\right)$ was calculated according to the following equation:

$$
\rho_{c}=\frac{W_{a}}{W_{a}-W_{w}}
$$

Where, $\mathrm{W}_{\mathrm{a}}$ and $\mathrm{W}_{\mathrm{w}}$ are the masses of the specimen in air and water, respectively [5][2][13].

Microstructure investigation is conducted on the polished sintered specimens using Field emission scanning electron microscope (FE-SEM) model QUANTA FEG250 equipped with energy dispersive (EDX) spectrometers, secondary electron (SE), and backscattered electron (BSE) detectors. X-ray diffraction (XRD) is applied to identify the phases and the crystallite of the size of the mixed powder after 
milling and sintered specimens. Bruker D8 advance diffractometer is used with $\mathrm{Cu} \mathrm{K}$-alpha radiation and operated at $40 \mathrm{kV}$ and $30 \mathrm{~mA}$. The FE-SEM was carried out in the Faculty of Petroleum \& Mining Engineering, Suez University, Egypt. The XRD was carried out in the Central Metallurgical R \& D Institute (CMRDI) in Cairo, Egypt.

The peak broadening has been used to calculate the crystallite size (D) produced during the milling process using Scherer's formula.

$$
D=\frac{k \lambda}{\beta \cos \theta}
$$

Where, $\mathrm{K}$ is a constant $(\mathrm{K}=0.94), \square$ is the $\mathrm{X}$-ray wavelength (1.5406 $\AA$ ), $\beta$ is the full width of the major $\mathrm{x}$-ray diffraction peak at its half maximum intensity in radian, and $\Theta$ is the Bragg angle [31]. Microhardness is measured along the polished surface of the sintered specimen's diameter by $2.5 \mathrm{~mm}$ step size using a Vickers hardness tester. The test was done under $300 \mathrm{~g}$ load for a $15 \mathrm{sec}$ dwell time.

Compression was carried out using a universal testing machine of $350 \mathrm{KN}$ capacity, INSTRON Model (4208-002), on specimens with $10 \mathrm{~mm}$ diameter and 12 $\mathrm{mm}$ height. The applied crosshead speed was 0.05 $\mathrm{mm} / \mathrm{sec}$, and the test was established at room temperature. Microhardness and Compression were carried out in the Faculty of Petroleum \& Mining Engineering, Suez University, Egypt.

Dry sliding wear tests are conducted using TNO Tribometer-block-on-ring wear test machine. The tested specimen dimensions prepared for wear test were $7 \times 5 \mathrm{~mm}^{2}$ and $12 \mathrm{~mm}$ long with its axis parallel to the pressing direction. The rotating sliding ring made of 63 HRC steel has a $73 \mathrm{~mm}$ diameter. The test is performed at $350 \mathrm{rpm}$ for $10 \mathrm{~min}$, and a load of $10 \mathrm{~N}$. The wear test was carried out in the Central Metallurgical R \& D Institute (CMRDI) in Cairo, Egypt.

The wear rate is determined according to the following equation [32]:

$$
\text { Wear Rate }=\frac{\Delta w}{T}
$$

Where $\Delta \mathrm{W}=\left(\mathrm{w}_{1}-\mathrm{w}_{2}\right)=$ Weight loss $(\mathrm{g}), \mathrm{w}_{1}$ and $\mathrm{w}_{2}$ are the weights before and after testing, respectively, and $\mathrm{T}$ is the sliding time $(\mathrm{Sec})=600 \mathrm{sec}$.

\section{Results and Discussion}

\subsection{Investigation of Al - TiC Powders}

\subsubsection{XRD Investigation of Used Powders}

Fig. 2 (a) and (b) show the XRD patterns of the asreceived pure $\mathrm{Al}$ and $\mathrm{TiC}$ powders, indicates the purity of raw materials. The revealed characteristic peaks in the XRD pattern were consistent with JCPDS file JCPDS Card No. 01-1180 and Card No. 32-1383 for Al and, TiC, respectively [33][34].
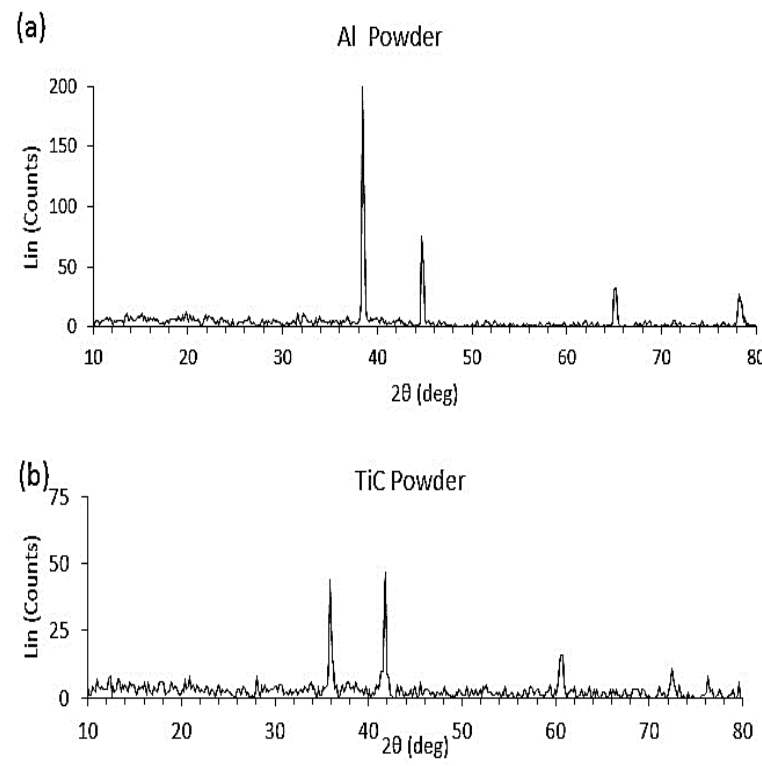

Fig. 2 XRD patterns of the as-received (a) Al powder and (b) TiC powder.

\subsubsection{Microstructure Examination of Al and TiC Powders}

The FE-SEM images for both $\mathrm{Al}$ and $\mathrm{TiC}$ powders are shown in Fig.3 (a) and (b), respectively. It indicated that $\mathrm{Al}$ particles have a spherical shape with particle size ranges from 5 up to $30 \mu \mathrm{m}$, while $\mathrm{TiC}$ has an angular (faceted or sharp-cornered) shape with particle size 0.5 up to $1 \mu \mathrm{m}$.

\subsubsection{XRD Al-TiC Composite Powders after MT}

The XRD patterns of $\mathrm{Al}$ mixed with 5, 10, and $20 \mathrm{wt}$. $\% \mathrm{TiC}$ powder composites milled at three milling times 6, 24, and 48 hr. are shown in Figs. 3 and 4. Few main peaks of these powders are visible. The results indicated that no new phases had been formed during the milling process at all milling times. This can be attributed to the lower heat produced from the milling process, which is not sufficient for forming any intermetallic or compounds between aluminium and 
titanium carbide according to the phase diagram of $\mathrm{Al}$ with $\mathrm{TiC}$ [2].
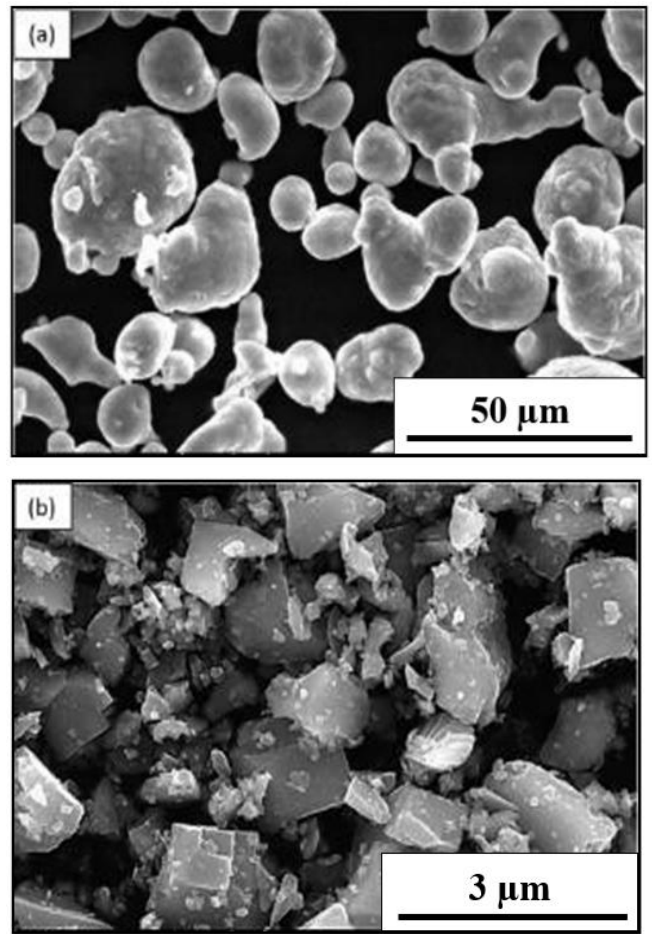

Fig. 3 FE-SEM images for; (a) Al powder and (b) TiC powder.

By increasing the milling time, the diffraction peaks of TiC powder become broader, and their relative intensities are decreased. This may be attributed to the strong collision of the mixed powders with the balls and walls of the container during the milling process. Thus, the particle size is decreased with a longer [28]. From Fig. 4, it can be observed that increasing TiC percent of the volume fraction led to more broadening, shifting, and decreasing in the intensity of the Bragg peaks. Moreover, the addition of $\mathrm{TiC}$ particles led to decreasing. The crystallite size of aluminium, as TiC is a hard-ceramic material that acts as an internal ball. The calculated average crystallite/domain size at different milling times and different weight percent of $\mathrm{TiC}$ are listed shown in Fig. 5.

\subsubsection{Microstructure Investigation Al-TiC Composite Powders after MT}

Fig. 6 (a), (b), and (c) show FE-SEM of the mixed composite powders. To study the effect of milling time on the microstructure of Al-TiC mixed powders, specimen containing $10 \mathrm{wt}$ \% $\mathrm{TiC}$ was chosen 6,24 , and $48 \mathrm{hr}$. milling time. The microstructural evolution of the milled powders at different milling times reveals that the particle shape, size, and uniformity of $\mathrm{TiC}$ powders dispersion in the aluminium matrix are significantly influenced by the milling time [26]. For example, after $6 \mathrm{hr}$. of the milling process, irregularly shaped $\mathrm{TiC}$ particles are fractured and become finer, and the average particle size is decreased from $1 \mu \mathrm{m}$ to $202 \mathrm{~nm}$. However, the variations of particle size in the milled powder exhibited a large degree of nonuniformity.

The distribution of TiC particles in the aluminium matrix has been observed. By increasing the milling time up to $24 \mathrm{hr}$., the milled powders were fractured intensively to form fine and ellipsoidal particles, as shown in Fig. 6 leading to further reduction in the average particle size from $202 \mathrm{~nm}$ to $186 \mathrm{~nm}$. Consequently, a homogeneous structure and broad range particle-size distribution are produced. Even at a higher milling time of $48 \mathrm{hr}$. as evident in Fig. 8, the particles are finer and more homogeneous in it is structured. As a result, the particle is reduced from $186 \mathrm{~nm}$ to $64 \mathrm{~nm}$, with further refinement to the nanoscale.

By comparing the morphology of specimens shown in Fig. 6 and 8, it can be noticed that for BPR (35:1) the ratio of welding to fracture of the particles at $24 \mathrm{hr}$. and $48 \mathrm{hr}$. milling time has been less than the one at $6 \mathrm{hr}$. milling time and this means that by increasing the milling time more refining of $\mathrm{Al}$ and $\mathrm{TiC}$ particles with more uniform distribution in the $\mathrm{Al}$ matrix takes place.

\subsection{Composite Characterization}

\subsubsection{XRD Investigation}

The XRD patterns of Al-based composites reinforced with 5, 10, and $20 \mathrm{wt}$. \% TiC samples milled for 6, 24, and $48 \mathrm{hr}$. are shown in Figs. 7 (a), (b), and (c) respectively. These figures show no new phases are formed between aluminium and titanium carbide during the sintering process up to 24 hours MT. While for $48 \mathrm{hr}$. milling time MT, (Al - $20 \mathrm{wt}$. \% TiC) samples, new peaks have appeared corresponding to the $\mathrm{Al}_{4} \mathrm{C}_{3}$ compound. This may be attributed to increasing the chance for the chemical reaction between $\mathrm{Al}$ and $\mathrm{TiC}$ for a high TiC percent of $20 \mathrm{wt} . \%$ and high MT of $48 \mathrm{hr}$. which increases the surface area of both $\mathrm{Al}$ and $\mathrm{TiC}$ due to the refinement of the particle size under the effect of hard ceramic TiC particles and large milling time, as detected from the SEM images. $\mathrm{Al}_{4} \mathrm{C}_{3}$ phase is often formed as an undesirable reaction product between $\mathrm{Al}$ and $\mathrm{TiC}$ during the sintering process [35]. 

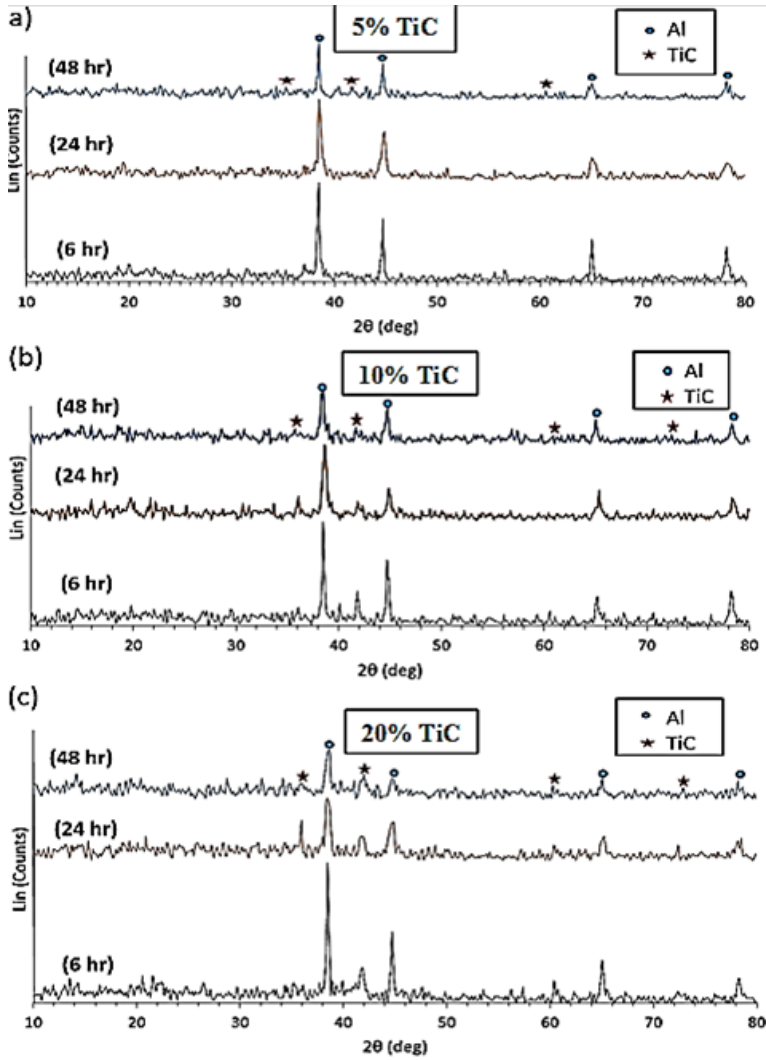

Fig. 4 XRD patterns for Al-TiC composites at various milling times.

\subsubsection{Microstructure investigation}

Figs. 8a, b, and c show the FE-SEM micrograph of Al-TiC composites reinforced with 10 wt. $\%$ of $\mathrm{TiC}$ with milling time 6,24 , and $48 \mathrm{hr}$. respectively. The distribution of the reinforcement $\mathrm{TiC}$ particles in the aluminium matrix has been observed. Fig. 8a reveals that after $6 \mathrm{hr}$. milling time, the large TiC particles are agglomerated during the milling process; the shape of the particles is deformed. Also, cold welding and fracture of particles were occurred due to the highenergy collision during the milling process. Those events may change particle shape, decrease the particle size, and form layered structures [36].

Fig. $8 \mathrm{~b}$ and $8 \mathrm{c}$ represent the microstructure of Al-10 wt. $\%$ TiC composite after $24 \mathrm{hr}$. and $48 \mathrm{hr}$., MT, respectively. The small particles are distributed homogenously among large particles (agglomeration of many small particles together) and nearly uniform particle size. Also, Fig. 8 shows that TiC particles are embedded in the aluminium matrix and distributed homogeneously all over the Al matrix. Increasing the milling time, the $\mathrm{TiC}$ and $\mathrm{Al}$ particles become finer.

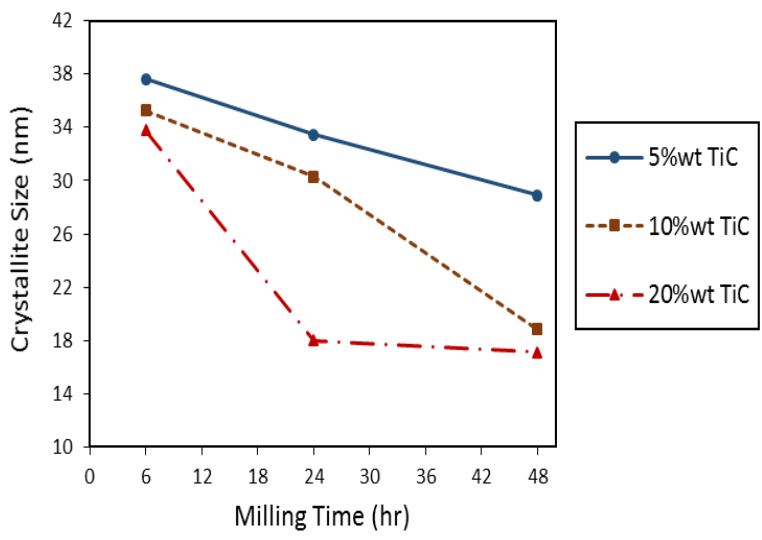

Fig. 5 Relation between crystallite size and milling time for $\mathrm{Al}-5,10$, and $20 \mathrm{wt}$ \% $\mathrm{TiC}$ specimens.
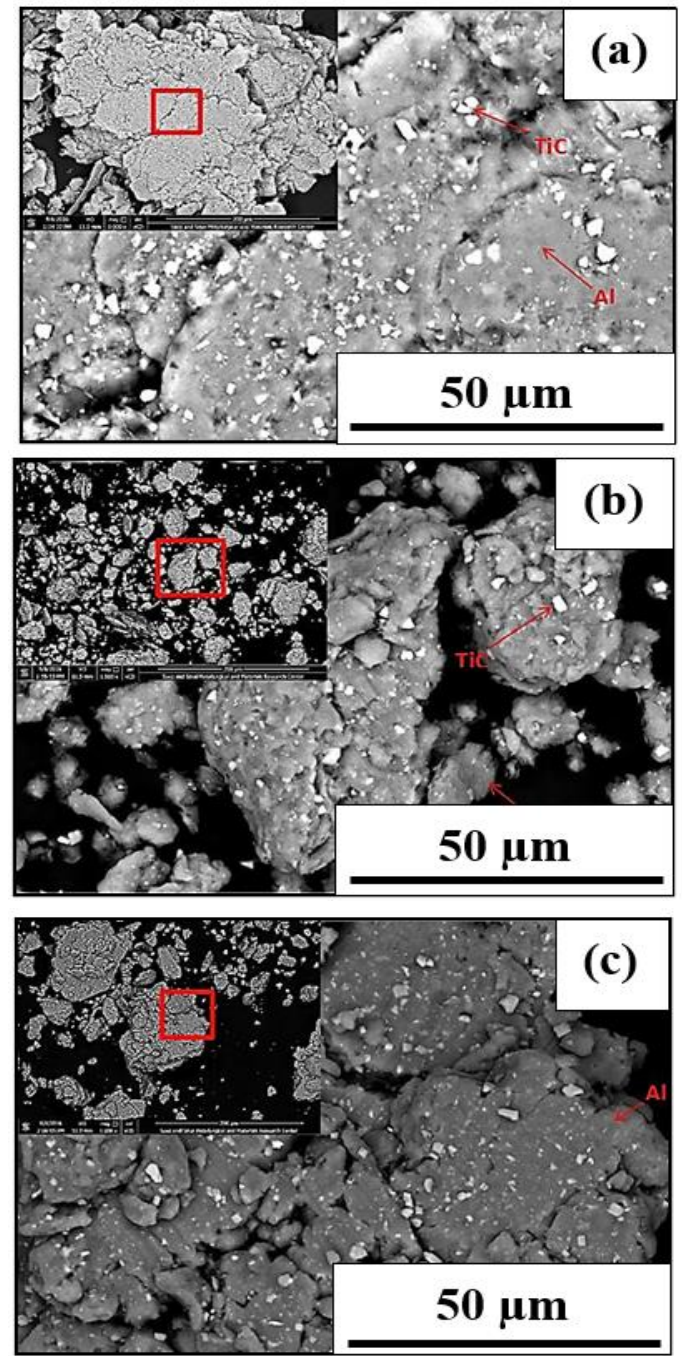

Fig. 6 FE-SEM for Al-10 wt. \% TiC (a) after 6 hr. milling, (b) after $24 \mathrm{hr}$. milling, and (c) after $48 \mathrm{hr}$.

This may be attributed to the higher energy produced among the balls, $\mathrm{TiC}$, and $\mathrm{Al}$ particles and the container 
wall, which produces impact energy that is sufficient for the fracture of the brittle $\mathrm{TiC}$ particles into the nanoscale enhances the distribution of $\mathrm{TiC}$ particles in Al matrix. The fine brittle $\mathrm{TiC}$ particles are distributed on the softer Al particles with no agglomeration of voids [37].

\subsubsection{EDS analysis}

Fig. 9 shows the EDS analysis coupled to FESEM for Al-10 wt. \% TiC specimen milled at $48 \mathrm{hr}$. Three peaks correspond to $\mathrm{Al}, \mathrm{Ti}$, and $\mathrm{C}$. Those belong to the $\mathrm{Al}$ matrix, $\mathrm{TiC}$ reinforcement, and the titanium metal produced as a by-product from the reaction between $\mathrm{Al}$ and $\mathrm{TiC}$ during the sintering process. This good indication for the homogeneous distribution of $\mathrm{TiC}$ all over the $\mathrm{Al}$ matrix.

\subsubsection{Density measurement}

Fig. 10 shows the relation between the theoretical density of the prepared specimens and $\mathrm{TiC}$ percent. TiC percent increases the densities, increasing gradually, which can be attributed to the higher density of TiC $4.93 \mathrm{~g} / \mathrm{cm}^{3}$ than that of Al $2.73 \mathrm{~g} / \mathrm{cm}^{3}$. The presence of minimal porosity in composite materials supported by the experimental density values can be attributed to particle refinement at a high milling time.

Also, Fig. $11 \mathrm{a}, \mathrm{b}$, and c presents the effect of milling time on the densification of Al-TiC composites for 5, 10 , and 20 wt. \% TiC specimens respectively, one behavior is observed, for 5 and $10 \mathrm{wt}$ \% TiC samples which is the decrease of density from $0 \mathrm{hr}$. MT to $6 \mathrm{hr}$. MT and gradual increasing up to $24 \mathrm{hr}$. MT then decreases again for $48 \mathrm{hr}$. MT. Decreasing the density from 0 MT up to $6 \mathrm{hr}$. MT may be attributed to the insufficient milling time that caused the reduction of particle size and good distribution of $\mathrm{TiC}$ particles in the Al matrix, so $6 \mathrm{hr}$.

MT is not suitable; consequently, the density is decreased. But by increasing MT from $6 \mathrm{hr}$. up to $24 \mathrm{hr}$. the density increased. This can be explained by the refinement and reduction of the particle size because of MT in which, by increasing the milling time from $6 \mathrm{hr}$. up to $24 \mathrm{hr}$. more collisions take place between the mixed powders, with the milling balls and container wall, this leads to more impact energy which causes fracture of the brittle $\mathrm{TiC}$ which enhances the interaction between $\mathrm{Al}$ and $\mathrm{TiC}$ particles that increases the densification [36].
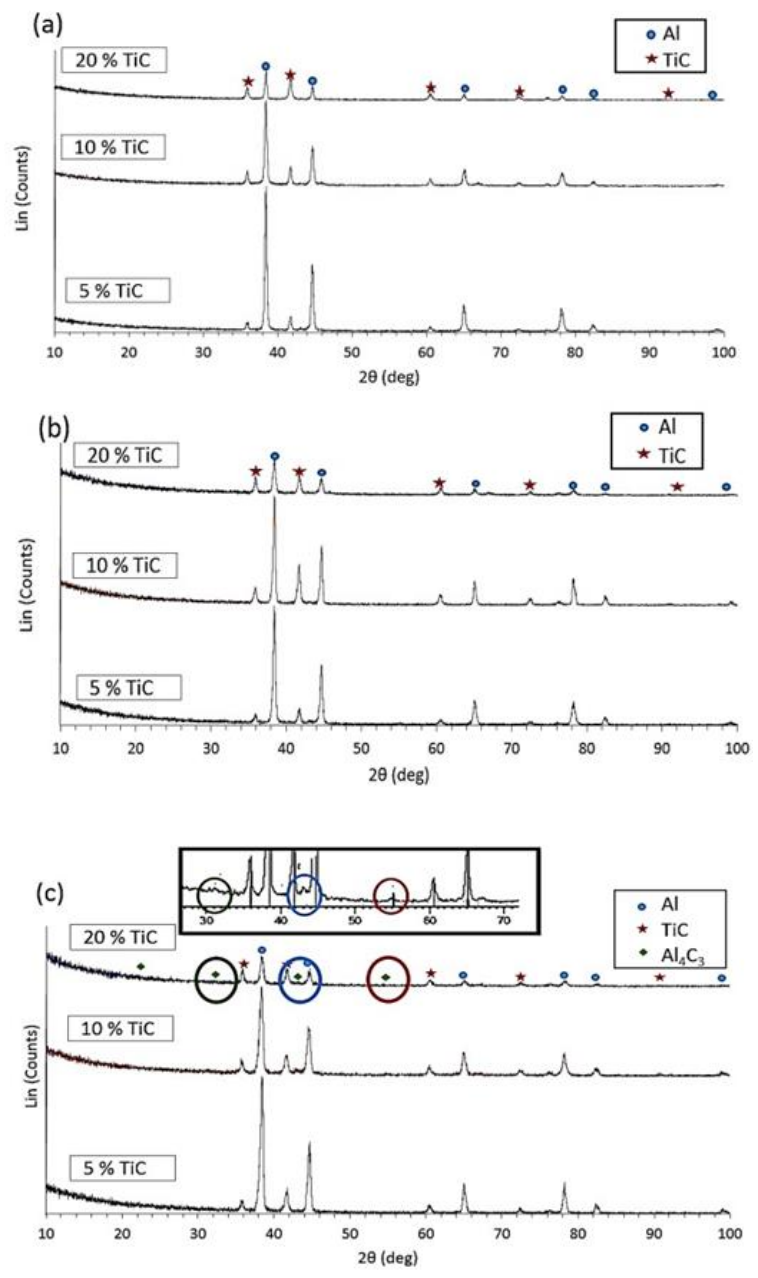

Fig. 7 XRD patterns of Al-5, 10, and 20 wt. \% TiC composites after different milling times (a) $6 \mathrm{hr}$., (b) $24 \mathrm{hr}$. and (c) $48 \mathrm{hr}$.

But for $48 \mathrm{hr}$. MT the density is decreased due to the formation of the $\mathrm{Al}_{4} \mathrm{C}_{3}$ phase, which is detected from XRD results with a lower density $(2.36 \mathrm{~g} / \mathrm{cm} 3)$ than $\mathrm{Al}$ and TiC. Also, the presence of hard ceramic $\mathrm{Al}_{4} \mathrm{C}_{3}$ phase lowers the wettability with $\mathrm{Al}$ particles which causes a gap that leads to the formation of pores and voids decreases the density [3]. This restricts the densification due to decreasing the backing ability of the powder owing to increasing the deformation and hardening of the particles [37]. Therefore, increasing the milling time has a detrimental effect on densification, for $20 \mathrm{wt}$. \% TiC samples, the behavior is different, in which the density is nearly constant for $0,6,12 \mathrm{hr}$. MT then decreased for $24 \mathrm{hr}$. and $48 \mathrm{hr}$. MT. The properties related to densification in terms of bulk density and the sintered specimens are presented in Fig. 15. 

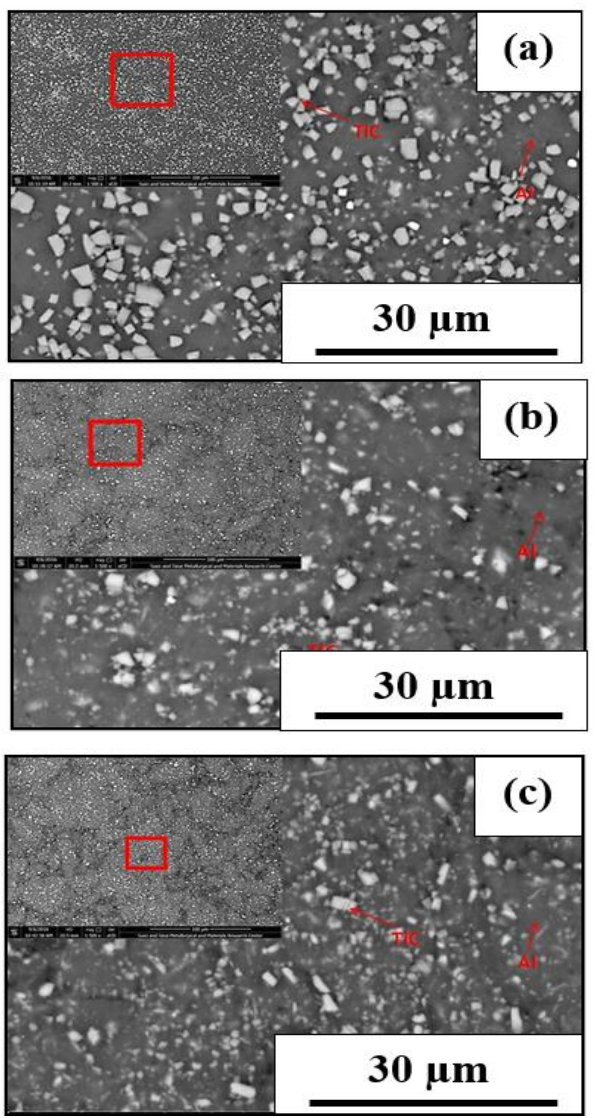

Fig. 8 FE-SEM image for sintered Al-10 wt. \% TiC (a) after 6 hr. milling, (b) after 24 hr. milling, and (c) after 48 hr. milling.
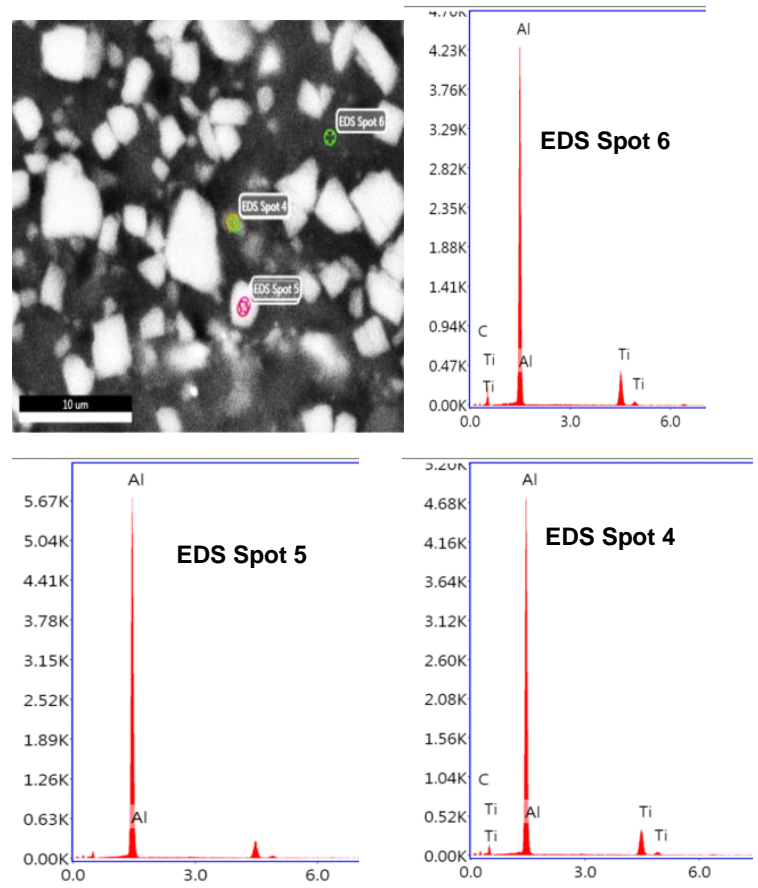

Fig. 9 EDS analysis for Al-10 wt. \% TiC composite milled at $48 \mathrm{hr}$. MT.

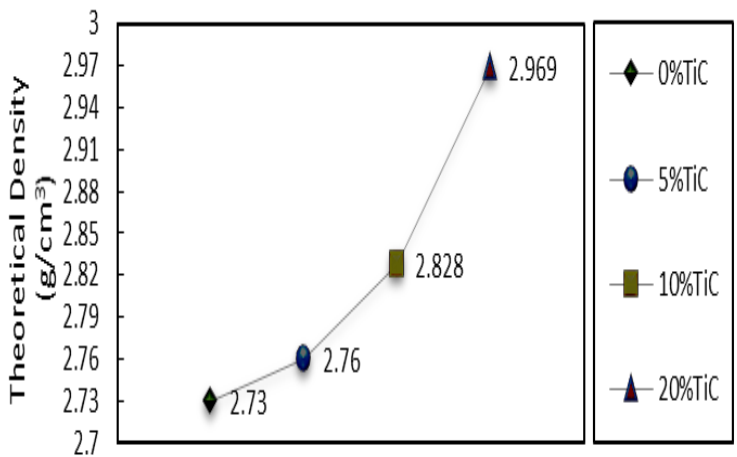

Weight Percent of TiC

Fig. 10 Effect of TiC percent on the theoretical density of Al-TiC composites.

The apparent porosity is inversely proportional with their bulk densities, and a significant increase of the apparent porosity and decreases in the bulk density after $48 \mathrm{hr}$., MT are noticed [38].

\subsubsection{Hardness Test}

Hardness is an actual mechanical test for Al-TiC composite applications. The variation in the hardness values can be explained by considering two factors, increasing reinforcement content and milling time. The results show that the hardness values increase gradually with increasing TiC content. Fig.12 displays the average values of the macro hardness of the prepared specimens as a function of milling time.

It shows that by increasing $\mathrm{TiC}$ percent and milling time, the macro hardness increases up to $20 \mathrm{wt}$. \% TiC and $24 \mathrm{hr}$. milling time. The addition of $\mathrm{TiC}$ particles has an appositive effect on hardness values. This is expected because hard $\mathrm{TiC}$ particulates act as a barrier to the dislocation movement within the matrix and exhibit greater resistance to indentation of the hardness tester. In optimal levels of reinforcing particulates, the actual inter-particle distance becomes near to the ideal expected distance; therefore, the effect of the Orowan strengthening mechanism increases. Also, the addition of hard ceramic $\mathrm{TiC}$ powder acts as a milling agent that reduces the particle size of the $\mathrm{Al}$ matrix. So, the hardness is increased, which agrees with the Hall-Petch equation, reveals that hardness is inversely proportional with the particle size. 
Also, the reduction of particle size of both $\mathrm{Al}$ and $\mathrm{TiC}$ enhances the hardness in which $\mathrm{TiC}$ size is lowered to the nanoscale. But for $48 \mathrm{hr}$. milling time, the hardness was decreased due to the formation of hard undesirable $\mathrm{Al}_{4} \mathrm{C}_{3}$ phase by a higher percent which is non-wettable with $\mathrm{Al}$ that causes the formation of pores. Also, by increasing the milling time to $48 \mathrm{hr}$. repeated coldwelding fracturing and re-welding has happened. This causes a heterogeneous distribution of large and small particles in the matrix as shown in the microstructure in Fig. 8 (c), which has a negative effect on the hardness value.
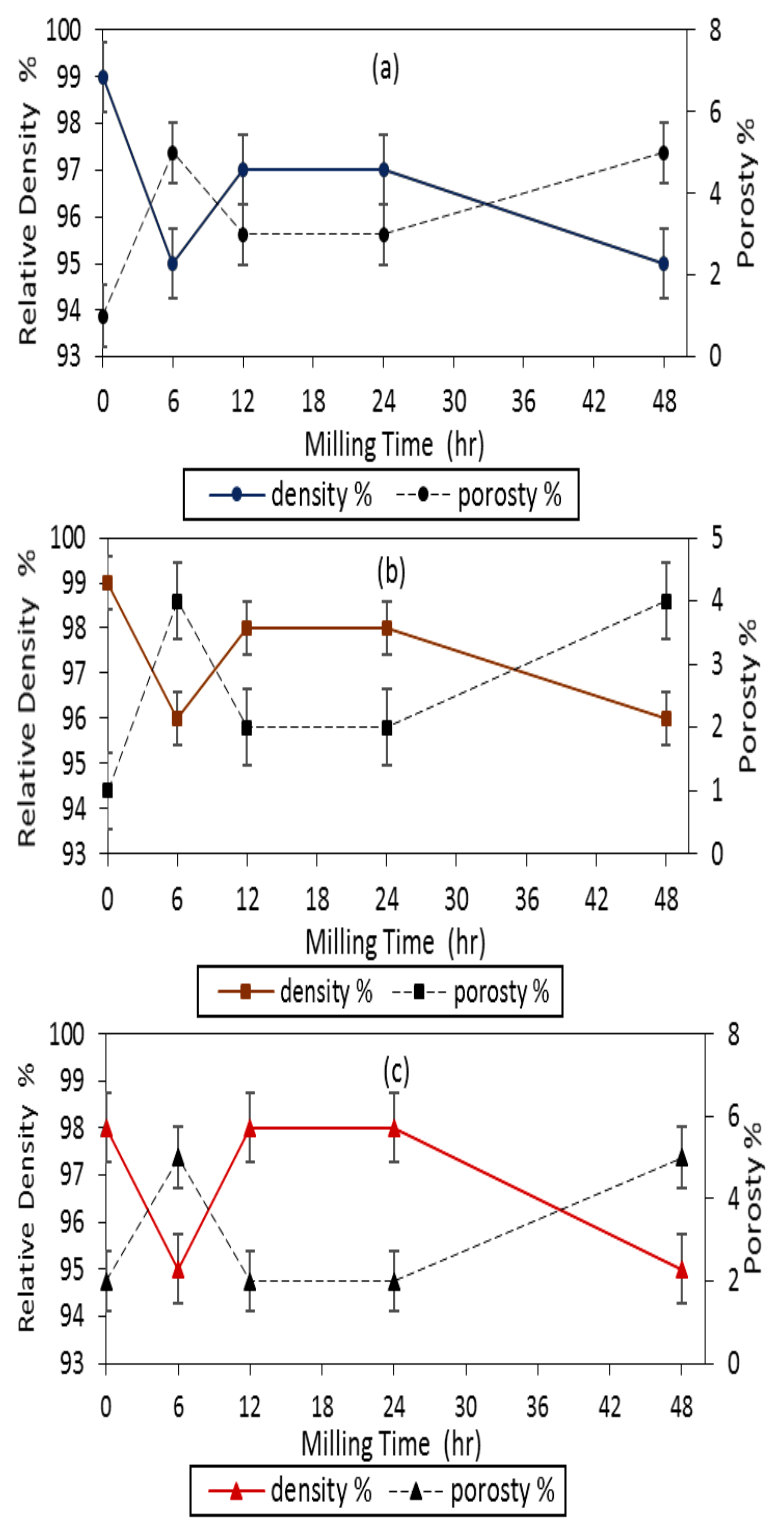

Fig. 11 Relative density and apparent porosity of (a) Al-5 wt. \% TiC, (b) Al-10 wt. \% TiC and (c) Al20 wt. $\%$ TiC, after different milling times.

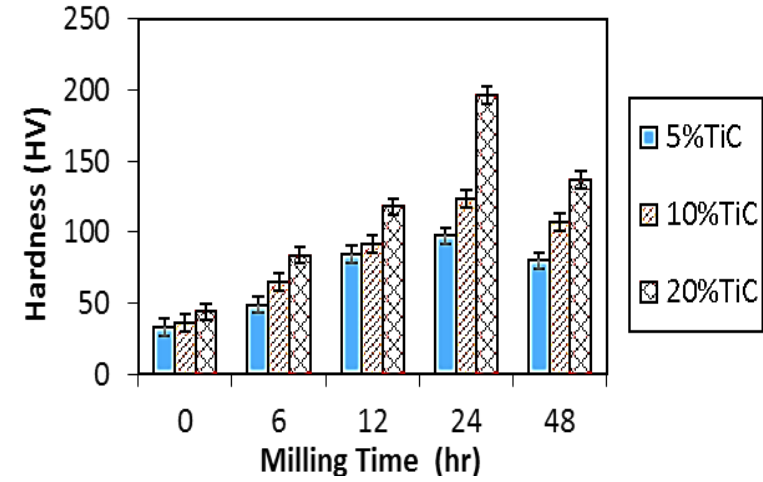

Fig. 12 Effect of milling time on the hardness values of $\mathrm{Al}-5,10$, and $20 \mathrm{wt}$ \% TiC composites.

\subsubsection{Compression Test}

Fig. 13 shows the compression strength values of (Al-5, 10, and 20 wt. \% TiC) composites milled at 0, 6, 12, 24, and $48 \mathrm{hr}$. The compression strength increases by increasing both $\mathrm{TiC}$ percent and milling time up to $24 \mathrm{hr}$. then decreases for $48 \mathrm{hr}$. milling time. This can be explained based upon both density and microstructure. As the density increases, the compression strength is increased gradually where the pores are considered a nucleus for crack initiation and propagation. So, the specimens milled for $48 \mathrm{hr}$. have the lowest compression strength as they possess the highest porosity. Also, as the $\mathrm{TiC}$ percent and milling time are increased, the particles become finer, and a reduction in the particle size is achieved, enhancing the hardness and the strength of the specimens [2]. Thus, the ultimate strength of the prepared specimens increases and the plastic deformation decreases gradually, which agrees with the hardness results of all specimens.

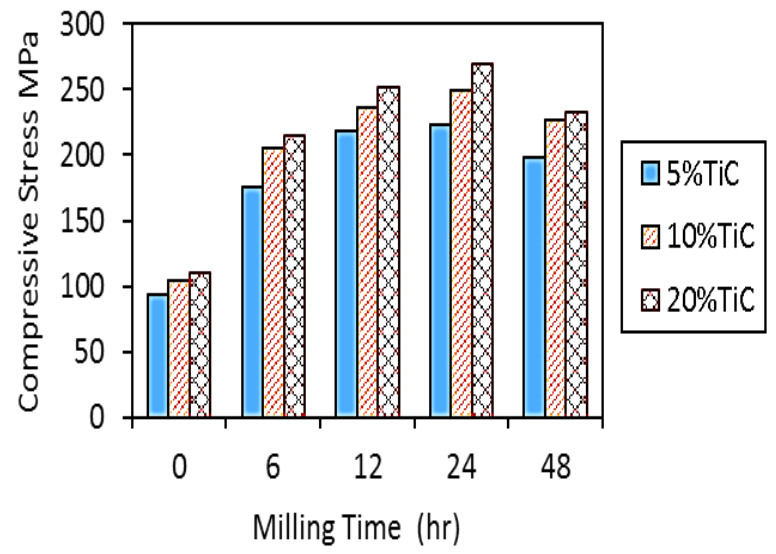

Fig. 13 Effect of milling time on the compression strength of Al-5, 10, and 20 wt. \% TiC composites. 


\subsubsection{Wear Test}

The relation between the milling time and $\mathrm{TiC}$ percent with the wear rate of Al-TiC composites is shown in Fig. 14. As TiC content and milling time increases, the wear rate decreases; this may be attributed to the presence of hard ceramic material as $\mathrm{TiC}$, which increases the strength of the specimens. Also, the refinement of particles due to the milling process reduces the particle size, increases densification, and decreases porosity. So, the specimens resist the wear due to high strength. This is in good agreement with the hardness and compression strength results [2].

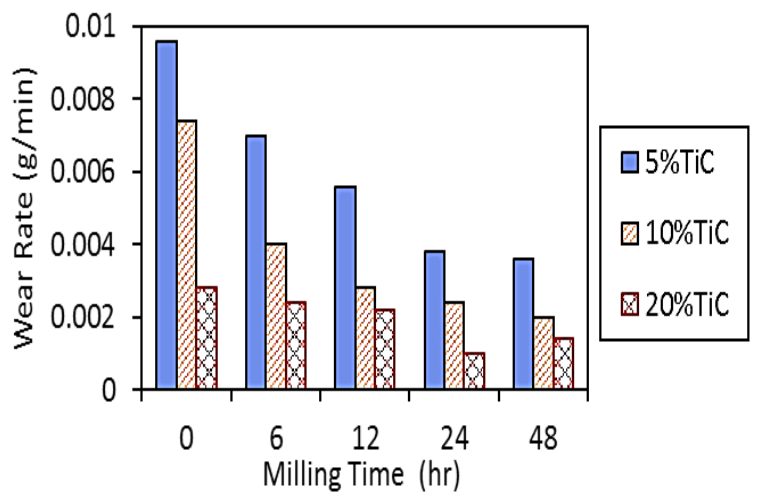

Fig. 14 Effect of milling time on the wear rate of Al-5, 10 , and 20 wt. \% TiC composites.

For $20 \mathrm{wt}$. \% TiC specimens milled for $48 \mathrm{hr}$., the wear rate increases more than $24 \mathrm{hr}$. milling time due to the higher porosity, non-homogeneous distribution of small and large particles which facilitate the wear rate. Fig. 14 shows the wear weight loss of all specimens. Based on the results, the weight loss decreases by increasing the $\mathrm{TiC}$ percent. The main reason for this improvement is related to the hardness enhancement after adding optimal levels of reinforcement. The maximum wear resistance enhancement is for decreases with increasing $\mathrm{TiC}$ up to $5 \mathrm{wt}$. \%. The results indicated that the wear rate of the composites decreases with increasing $\mathrm{TiC}$ weight fraction and the improvement trend gradually decreases with increasing reinforcement content, but with increased milling time up to $48 \mathrm{hr}$. increase the wear weight loss. It is generally believed that the incorporation of hard particles in aluminium alloys contributes to improving the wear resistance of the base alloy. TiC improves the sliding wear resistance of aluminium alloys. $\mathrm{TiC}$ is the hard particle that resists the destructive action of abrasion and protects the surface, so by increasing its percent, the wear resistance enhances [25].
SEM micrographs of worn surfaces of specimens under $10 \mathrm{~N}$ applied load is presented in Fig.15 (a, b, and c) for $6,24 \& 48 \mathrm{MT}$. The worn surfaces contain grooves parallel to the sliding direction. The surface of 10 wt. \% TiC exhibits extensive nubs and dips because of the domination of delaminating wear mechanism. An extensive coarse groove is typical features associated with abrasive wear, in which the hard TiC particles are present in-between the pin and disc, plow or cut into the pin causing wear weight loss by the removal of the material [39].

Fig. 15a shows the wear tracks of Al matrix composites, and it shows strong delamination and fracture of the transfer layer caused by the abrasive action of the hard ceramic particles that causes the cutting with subsequent delamination and fracture of the sample's surface.
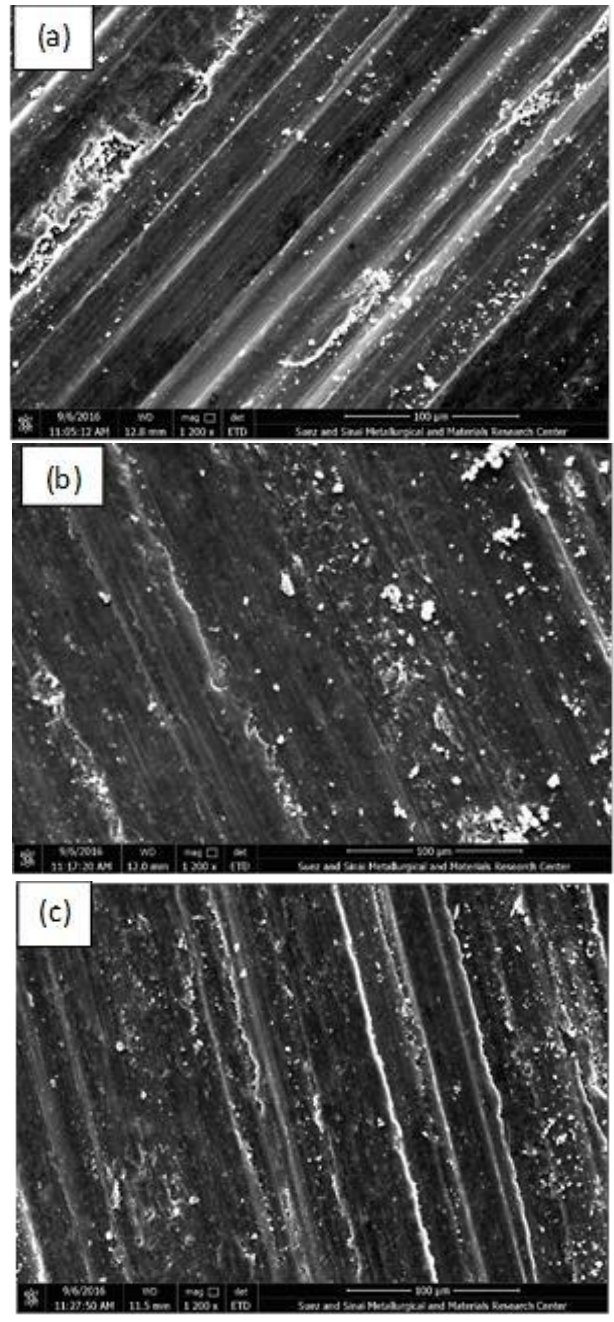

Fig. 15 Micrographs of wear surface of Al-10wt.\% TiC specimens (a) 6hr. (b) 24hr., and (c) 48hr. 
Fig. $15(b, c)$ shows distinct grooves and ridges running parallel to one another in the sliding direction. The micrographs show that the grooves are deeper and wider in the Al-TiC samples, as compared with the samples examined under the same conditions. In the case of composites, a thick layer is observed, which protects the underlying matrix from being in contact with the sliding counterpart, so decreasing in the wear rate is recorded. This transfer layer formed provides a protective cover, thus inhibiting the metal-metal interaction. Therefore, less wear rate has been observed [39]. Fig. 15b, which helps to infer that the Al-10 wt. \% TiC after $24 \mathrm{hr}$. MA milling time composite exhibits superior wear resistance compared to other AMMCs and matrix alloy.

Some local plastic deformation and material smearing indicate adhesive wear. For the applied load, the worn surface of the composites is becoming smoother by gradually increasing the percentage of the reinforcing material. The recognized wear mechanism in this work agrees with a report of adhesion and micro plowing in $\mathrm{Al}-\mathrm{TiC}$ composite with particle sizes from 4 to $13 \mu \mathrm{m}$, while bigger particles $(29 \mu \mathrm{m})$ cause the delamination and abrasive wear, consequently an increase in the wear rate takes place [40]. By increasing the applied load, the wear mechanism is changed, and the delamination wear is observed.

\section{Conclusions} that:

Based on the present results, it could be concluded

1. Al-TiC composite can be prepared successfully by powder metallurgy technique.

2. The XRD results of (Al - 5, 10, and $20 \mathrm{wt}$. \% TiC) composites milled up to $24 \mathrm{hr}$. MT showed no peaks rather than those corresponding to $\mathrm{Al}$ and $\mathrm{TiC}$.

3. The XRD results of all specimens milled at $48 \mathrm{hr}$. showed both $\mathrm{Al} \& \mathrm{TiC}$ besides peaks corresponding to aluminum carbide $\left(\mathrm{Al}_{4} \mathrm{C}_{3}\right)$ phase, which is formed.

4. The crystallite size of Al decreased with increasing the milling time as well as $\mathrm{TiC}$ percent.

5. The microstructure of Al-TiC composites indicates a reduction in the particle size of the $\mathrm{Al}$ matrix and a homogeneous distribution of $\mathrm{TiC}$ all over the $\mathrm{Al}$ matrix by increasing both $\mathrm{TiC}$ percent and MT.
6. The relative density of Al-TiC composites increases with increasing both TiC content, MT up to $24 \mathrm{hr}$. then decreased for $48 \mathrm{hr}$. MT.

7. Hardness, compression strength and wear resistance are improved by increasing both TiC content and MT up to $24 \mathrm{hr}$.

8. Specimens at $48 \mathrm{hr}$. have low hardness as well as compression strength due to the formation of a new phase of $\left(\mathrm{Al}_{4} \mathrm{C}_{3}\right)$.

9. The microstructure of worn surfaces of Al-TiC composites by FE-SEM indicated that the roughness of worn surfaces of the composites is reduced with increasing MT up to $24 \mathrm{hr}$.

\section{Acknowledgment}

The authors acknowledge the kind support by the researchers and the technicians of the Central Metallurgical R \& D Institute (CMRDI) in Cairo, Egypt, and thank them for their collaboration.

\section{References}

[1] V. Yadav, Spark plasma sintering of aluminum matrix composites, ProQuest Diss. Theses. (2011) 107.

http://search.proquest.com/docview/899269038?ac countid=27795.

[2] K.A. Khalil, E.S.M. Sherif, A.M. Nabawy, H.S. Abdo, W.W. Marzouk, H.F. Alharbi, Titanium carbide nanofibers-reinforced aluminum compacts, a new strategy to enhance mechanical properties, Materials (Basel), 9 (2016) 1-14. https://doi.org/10.3390/ma9050399.

[3] M. A. Ibrahim, Y. Sahin, A. Y. Gidado, M. T. Said, Mechanical Properties of Aluminium Matrix Composite Including $\mathrm{SiC} / \mathrm{Al}_{2} \mathrm{O}_{3}$ by Powder Metallurgy-A Review, (GSJ, ISSN 2320-9186) , 7 (2019) 23-38. https://doi.org/212464700.

[4] S. Mallik, N. Ekere, C. Best, R. Bhatti, Investigation of thermal management materials for automotive electronic control units, Appl. Therm. Eng. 31 (2011) 355-362. https://doi.org/10.1016/j.applthermaleng.2010.09.0 23.

[5] I. Montealegre Melendez, E. Neubauer, P. Angerer, H. Danninger, J.M. Torralba, Influence of nanoreinforcements on the mechanical properties and microstructure of titanium matrix composites, Compos. Sci. Technol. 71 (2011) 1154-1162. https://doi.org/10.1016/j.compscitech.2011.04.005.

[6] A. Fathy, O. El-Kady, M.M.M. Mohammed, Effect of iron addition on microstructure, mechanical and magnetic properties of Al-matrix composite 
produced by powder metallurgy route, Trans. Nonferrous Met. Soc. China (English Ed. 25 (2015) 46-53. https://doi.org/10.1016/S10036326(15)63577-4.

[7] O.A. Elkady, S.A. Abolkassem, A.H. Elsayed, W.A. Hussein, K.F.A. Hussein, Microwave absorbing efficiency of $\mathrm{Al}$ matrix composite reinforced with nano-Ni/SiC particles, Results Phys. $12 \quad$ (2019) 687-700 https://doi.org/10.1016/j.rinp.2018.11.095.

[8] Y. Liu, Z. Yang, B. Tian, Y. Zhang, Z. Gu, A.A. Volinsky, Hot Deformation Behavior of the 20 vol.\% TiC/Cu-Al2O3 Composites, J. Mater. Eng. Perform. 27 (2018) 4791-4798. https://doi.org/10.1007/s11665-018-3586-1.

[9] C. Magnus, W.M. Rainforth, Spark plasma sintering (SPS) synthesis and tribological behaviour of MAX phase composite of the family Tin+1SiCn $(n=2)$, Wear. 438-439 (2019) 203062. https://doi.org/10.1016/j.wear.2019.203062.

[10] M. Aktar Zahid Sohag, P. Gupta, N. Kondal, D. Kumar, N. Singh, A. Jamwal, Effect of ceramic reinforcement on the microstructural, mechanical and tribological behavior of $\mathrm{Al}-\mathrm{Cu}$ alloy metal matrix composite, Mater. Today Proc. 21 (2020) 1407-1411.

https://doi.org/10.1016/j.matpr.2019.08.179.

[11] R.A. Khosroshahi, N. Nemati, M. Emamy, N. Parvini, A. Zolriasatein, Investigation of wear properties of Al-4.5wt.\% $\mathrm{Cu}$ nano-composite reinforced with different weight percent of $\mathrm{TiC}$ nano particles produced by mechanical alloying, $A d v$. Mater. Res. 545 (2012) 124-128. https://doi.org/10.4028/www.scientific.net/AMR.5 45.124 .

[12] M. Asif, K. Chandra, P.S. Misra, Development of Aluminium Based Hybrid Metal Matrix Composites for Heavy Duty Applications, J. Miner. Mater. Charact. Eng. 10 (2011) 1337-1344. https://doi.org/10.4236/jmmce.2011.1014105.

[13] I. Topcu, H.O. Gulsoy, N. Kadioglu, A.N. Gulluoglu, Processing and mechanical properties of $\mathrm{B} 4 \mathrm{C}$ reinforced $\mathrm{Al}$ matrix composites, J. Alloys Compd. $\quad 482 \quad$ (2009) 516-521. https://doi.org/10.1016/j.jallcom.2009.04.065.

[14] I.Y. Kim, B.J. Choi, Y.J. Kim, Y.Z. Lee, Friction and wear behavior of titanium matrix $(\mathrm{TiB}+\mathrm{TiC})$ composites, Wear. 271 (2011) 1962-1965. https://doi.org/10.1016/j.wear.2010.12.072.

[15] I. Solodkyi, O. Bezdorozhev, P. Loboda, High electrical conductive copper matrix composites reinforced with LaB6-TiB2 eutectic particles, $\begin{array}{llll}\text { Vacuum. } & 177 & \text { (2020) } & \end{array}$ https://doi.org/10.1016/j.vacuum.2020.109407.

[16] A.R. Kennedy, S.M. Wyatt, Characterizing particle-matrix interfacial bonding in particulate AlTiC MMCs produced by different methods, Compos. Part A Appl. Sci. Manuf. 32 (2001) 555$559 . \quad$ https://doi.org/10.1016/S1359$835 \mathrm{X}(00) 00052-\mathrm{X}$

[17] A.E. Karantzalis, S. Wyatt, A.R. Kennedy, The mechanical properties of Al-TiC metal matrix composites fabricated by a flux-casting technique, Mater. Sci. Eng. A. 237 (1997) 200-206. https://doi.org/10.1016/S0921-5093(97)00290-6.

[18] S. Solay Anand, B. Mohan, Enhanced hardness property in the development of Al-TiC composites through P/M techniques, Adv. Mater. Res. 548 (2012) 243-249. https://doi.org/10.4028/www.scientific.net/AMR.5 48.243.

[19] X.C. Tong, A.K. Ghosh, Fabrication of in situ TiC reinforced aluminum matrix composites, J. Mater. $\begin{array}{llll}\text { Sci. } & 36 & \text { (2001) 4059-4069. }\end{array}$ https://doi.org/10.1023/A:1017946927566.

[20] A. Canakci, S. Ozsahin, T. Varol, Prediction of Effect of Reinforcement Size and Volume Fraction on the Abrasive Wear Behavior of AA2014/B4Cp MMCs Using Artificial Neural Network, Arab. J. Sci. Eng. $39 \quad$ (2014) 6351-6361. https://doi.org/10.1007/s13369-014-1157-9.

[21] J.B. Fogagnolo, M.H. Robert, J.M. Torralba, Mechanically alloyed AlN particle-reinforced Al6061 matrix composites: Powder processing, consolidation and mechanical strength and hardness of the as-extruded materials, Mater. Sci. Eng. A. 426 (2006) 85-94. https://doi.org/10.1016/j.msea.2006.03.074.

[22] R. Senthilkumar, N. Arunkumar, M. Manzoor Hussian, Effects of Micro and Nano-Size $\mathrm{Al}_{2} \mathrm{O}_{3}$ Particle Reinforcement on Mechanical Behaviour of Extruded Aluminum Alloy Matrix Composite, Appl. Mech. Mater. 787 (2015) 617-621. https://doi.org/10.4028/www.scientific.net/amm.78 7.617 .

[23] N. Raghavendra, V.S. Ramamurthy, Effect of Particle Size and Weight Fraction of Alumina Reinforcement on Wear Behavior of Aluminum Metal Matrix Composites, International Journal of Innovative Research in Science, Engineering and Technology, 3 (2014) 11191-11198.

[24] A. Azimi, A. Shokuhfar, O. Nejadseyfi, H. Fallahdoost, S. Salehi, Optimizing consolidation behavior of Al 7068-TiC nanocomposites using Taguchi statistical analysis, Trans. Nonferrous Met. Soc. China (English Ed. 25 (2015) 2499-2508. 
https://doi.org/10.1016/S1003-6326(15)63868-7.

[25] L. Van Duong, N. Van Luan, N. Ngoc Anh, T. Bao Trung, L. Danh Chung, N. Quang Huan, D. Thi Nhung, P. Ngoc Minh, D. Dinh Phuong, P. Van Trinh, Enhanced mechanical properties and wear resistance of cold-rolled carbon nanotubes reinforced copper matrix composites, Mater. Res. Express. 7 (2020). https://doi.org/10.1088/2053$1591 / \mathrm{ab} 69 \mathrm{c} 1$.

[26] K.L. Firestein, S. Corthay, A.E. Steinman, A.T. Matveev, A.M. Kovalskii, I. V. Sukhorukova, D. Golberg, D. V. Shtansky, High-strength aluminumbased composites reinforced with $\mathrm{BN}, \mathrm{AlB} 2$ and AlN particles fabricated via reactive spark plasma sintering of Al-BN powder mixtures, Mater. Sci. $\begin{array}{lllll}\text { Eng. } & \text { A. } & 681 & \text { (2017) } & \text { 1-9. }\end{array}$ https://doi.org/10.1016/j.msea.2016.11.011.

[27] A. Canakci, T. Varol, A novel method for the production of metal powders without conventional atomization process, J. Clean. Prod. 99 (2015) 312 319. https://doi.org/10.1016/j.jclepro.2015.02.090.

[28] M.Z. Mehrizi, R. Beygi, G. Eisaabadi, Synthesis of $\mathrm{Al} / \mathrm{TiC}-\mathrm{Al} 2 \mathrm{O} 3$ nanocomposite by mechanical alloying and subsequent heat treatment, Ceram. Int. $42 \quad$ (2016) 8895-8899. https://doi.org/10.1016/j.ceramint.2016.02.144.

[29] A. Kumar, M.K. Chowrasia, U. Banerjee, M.K. Banerjee, Enhancing structural stability and physical properties of silver added iron-MWCNT composite prepared by high energy ball milling and spark plasma sintering, Diam. Relat. Mater. 111 (2021) 108228. https://doi.org/10.1016/j.diamond.2020.108228.

[30] Y. Zhang, Q. Wang, C.S. Ramachandran, Synthesis of carbon nanotube reinforced aluminum composite powder (CNT-Al) by polymer pyrolysis chemical vapor deposition (PP-CVD) coupled high energy ball milling (HEBM) process, Diam. Relat. Mater. $\quad 104 \quad$ (2020) 107748. https://doi.org/10.1016/j.diamond.2020.107748.

[31] S. Suwanboon, P. Amornpitoksuk, A. Haidoux, J.C. Tedenac, Structural and optical properties of undoped and aluminium doped zinc oxide nanoparticles via precipitation method at low temperature, J. Alloys Compd., 462 (2008) 335339. https://doi.org/10.1016/j.jallcom.2007.08.048.

[32] H. Fallahdoost, A. Nouri, A. Azimi, Dual functions of TiC nanoparticles on tribological performance of Al/graphite composites, J. Phys. Chem. Solids. 93 (2016) https://doi.org/10.1016/j.jpcs.2016.02.020.

[33] A. Nazarov, V.A. Safronov, R.S. Khmyrov, I. Shishkovsky, Fabrication of Gradient Structures in the Ni - Al System via SLM Process, Procedia IUTAM. $23 \quad$ (2017) 161-166. https://doi.org/10.1016/j.piutam.2017.06.017.

[34] V. Oliveira, R. Colaço, R. Vilar, Simulation of $\mathrm{KrF}$ laser ablation of Al2O3-TiC, Appl. Surf. Sci. 253 (2007) 7585-7590. https://doi.org/10.1016/j.apsusc.2007.03.070.

[35] S. Hashimoto, A. Yamaguchi, M. Koshino, Fabrication and characterization of TiC/Al composites, Mater. Sci. Eng. A. 265 (1999) 71-76. https://doi.org/10.1016/s0921-5093(99)00005-2.

[36] C. Suryanarayana, Mechanical alloying and milling, Prog. Mater. Sci. 46 (2001) 1-184.

https://doi.org/10.1016/S0079-6425(99)00010-9.

[37] C. Dos Santos Torres, L. Schaeffer, Effect of high energy milling on the microstruture and properties of Wc-Ni composite, Mater. Res. 13 (2010) 293$298 . \quad$ https://doi.org/10.1590/s151614392010000300004.

[38] Z. Liu, Q. Han, J. Li, A developed method for producing in situ $\mathrm{TiC} / \mathrm{Al}$ composites by using quick preheating treatment and ultrasonic vibration, Compos. Part B Eng. 43 (2012) 2429-2433. https://doi.org/10.1016/j.compositesb.2011.11.004.

[39] V. Ramakoteswara Rao, N. Ramanaiah, M.M.M. Sarcar, Dry sliding wear behavior of TiC -AA7075 metal matrix composites, Int. J. Appl. Sci. Eng. 14 (2016) https://doi.org/10.6703/IJASE.2016.14(1).27. 27-37.

[40] M. Ali, S. Falih, Synthesis and characterization of aluminum composites materials reinforced with $\mathrm{TiC}$ nano- particles, Jordan J. Mech. Ind. Eng. 8 (2014) 257-264. 